\title{
Preparedness Lessons from Modern Disasters and Wars
}

\author{
Saqib I. Dara, MD, FCCP ${ }^{a}$, J. Christopher Farmer, MD, FCCM ${ }^{b, c, d, *}$
}

\section{KEYWORDS}

- Disaster medicine $\bullet$ Critical care $\bullet$ Disaster planning

- Intensive care • Disasters • Chernobyl nuclear accident

In life, unlike chess, the game continues after checkmate.

Isaac Asimov, 1920-1992

In 2003, the severe acute respiratory syndrome (SARS) outbreak unmasked the vulnerability of health care professionals caring for these contagious patients. ${ }^{1,2}$ In some countries, $50 \%$ of the SARS casualties were health care workers. ${ }^{3} \mathrm{~A}$ tsunami in 2004 killed an estimated 230,000 people, mostly in Indonesia. ${ }^{4}$ In 2005, Hurricane Katrina struck the United States, an industrialized nation with enormous resources. Despite the presence of a substantial response infrastructure in the United States, news images revealed an initial paralytic aftermath with individuals "dying in the streets" and stranded critically ill patients in the shells of hospitals. Ensuing floods rendered intensive care units (ICUs) nonfunctional. ${ }^{5,6}$ News headlines in 2008 estimated that more than 100,000 people died in Myanmar $^{7}$ as a consequence of cyclone Nargis and almost 70,000 people died following earthquakes in China last spring. ${ }^{8}$

Fortunately, in the wake of these events, medical response to disasters significantly evolved. ${ }^{9-11}$ Most recent disasters around the world have witnessed brisk execution of well-structured, integrated response, albeit with occasional operational flaws. ${ }^{12,13}$ Much of this progress has occurred as a result of governmental policy shifts that followed disasters. ${ }^{14}$ In the United States, for instance, there has been a clear increase in focus on disaster preparedness since the events of September $11,2001 .^{15}$

\footnotetext{
a Critical Care Medicine, Al Rahba Hospital_Johns Hopkins International, Abu Dhabi, United Arab Emirates

b Critical Care Medicine, Mayo School of Graduate Medical Education, Mayo Clinic College of Medicine, Rochester, MN, USA

c Department of Medicine, Mayo Clinic College of Medicine, Rochester, MN, USA

d Program in Translational Immunovirology and Biodefense, Mayo Clinic College of Medicine, Rochester, MN, USA

* Corresponding author. Department of Medicine, Mayo Clinic College of Medicine, 200 First Street SW, Old Marian Hall, OL2-115, Rochester, MN 55905.

E-mail address: farmer.j@mayo.edu (J.C. Farmer).
} 
At the government level, we witnessed the creation of the Department of Homeland Security to streamline and improve the efficiency of multiple response agencies. ${ }^{16}$ In addition, the ongoing scientific, ${ }^{17,18}$ technical, ${ }^{19-21}$ and educational advances ${ }^{22-24}$ and their integration with disaster medicine ${ }^{25,26}$ have advanced our ability to respond to disasters. For example, we have increased capability of transporting very sick patients, ${ }^{27,28}$ improved early detection of unusual and previously unidentified microbes, ${ }^{29}$ and enhanced our ability to rapidly acquire information from disaster scenes through mobile telecommunications systems, global positioning, and telemedicine technologies. ${ }^{30}$

What lessons can we learn from these events and from other disasters over the last many decades? Despite the varied nature of these catastrophes, many critical care themes are common to all:

Planning matters - a lot! ${ }^{12,31,32}$

The absence of sufficient training and education equals confusion, uncertainty, and increased secondary casualties (including injuries and fatalities to health care professionals). ${ }^{33}$

The provision of critical care must include "portability," defined as the ability to provide credible, sustainable, sophisticated care outside of the normal confines of an ICU. ${ }^{9,34-36}$

Dispelling myths: It's too many casualties, so what possible impact would a (relative) "handful" of resources mean to this many patients?

To address these issues, we need to identify simple, broadly available technologies that can be universally employed. ${ }^{28,37}$

What follows is a representative, but not exhaustive, list of representative disasters that have occurred over the last few decades, with a summary of each disaster, as well as specific clinical lessons learned. Finally, we offer suggestions regarding how each of these disaster events should influence our current critical care preparedness planning.

\section{EVENT: CHERNOBYL NUCLEAR DISASTER}

\section{Summary}

On April 26, 1986, a large-scale nuclear disaster occurred at Chernobyl, a small town in Ukraine, which was a part of the Soviet Union. ${ }^{38,39}$ Compared with other large-scale disasters, such as the nuclear bomb detonations in Hiroshima and Nagasaki and exposure to cesium-127 in Brazil, ${ }^{40}$ this is the worst nuclear disaster in history. It resulted from overheating of a reactor core, while testing a safety procedure. An estimated 56 deaths occurred, including 28 radiation deaths among reactor operators and firefighters. ${ }^{41}$ Additionally, it is estimated that there may be have been hundreds of subsequent cancer occurrences among the adjacent population, as well as among the 6 million people who lived within the radiation fallout plume. ${ }^{42}$

\section{Relevance to Today and Clinical Teaching Points}

The medical literature contains little about the immediate response to the Chernobyl disaster. Even so, lessons can be learned about the gaps in reporting and communication and the secrecy of the authorities at the time. This failure to inform generated fear, rumors, and uncertainty. ${ }^{39}$

There could be very high rates of posttraumatic stress disorder after a major radiation exposure. Groups particularly at risk include children, pregnant women, mothers 
of young children, and emergency workers. Prevention is essential through openness and communication. ${ }^{43}$

Another important lesson from Chernobyl is that a major radiation incident also results in thermal and radiation burns, wounds, fractures, and other trauma injuries, thus adversely affecting the prognosis of the patient. The immune function may become compromised, predisposing patients to sepsis. Compromised immune function was observed for Chernobyl firefighters and should be a treatment priority. ${ }^{44}$

These lessons have assumed greater significance in the context of the current geopolitical realities. The ongoing oil crisis makes it likely that there will be more reliance on nuclear production of energy. Although global nuclear war may be less likely than in the past, terrorist use of radiologic weapons is an increasing threat. ${ }^{45}$

\section{Lessons for Critical Care}

- We often overlook the need to provide surveillance for posttraumatic stress disorder in our critical care health care professionals, as well as follow-up for patients and family members. Posttraumatic stress disorder may have more significant longer-term negative ramifications than we earlier believed. ${ }^{46}$

- It is anticipated that in the event of a nuclear disaster, a casualty stream would include significant numbers of patients with both traumatic injuries and radioactive contamination. Critical care preparedness should include provisions (ie, decontamination access) to deal with both problems. ${ }^{40}$

- Potassium iodide is touted as an "antidote" to "radiation poisoning." Remember, however, that this is protective only to the thyroid gland.

- Complete critical care planning includes a triage plan for radiation-exposure victims. This plan should incorporate a predictive matrix that projects severity of illness and probability of survival (based on probable radiation-dose exposure). Table 1 offers an example. Others employ more complicated methodologies, such as rate of lymphocyte depletion.

- The secondary radiation risk to health care workers from exposure to contaminated casualties (or their excreta, body fluids) is limited. ${ }^{41}$

\section{EVENT: BHOPAL DISASTER}

\section{Summary}

One of the worst chemical disasters in history occurred on December 2, 1984, in Bhopal, Madhya Pradesh, India. ${ }^{47}$ At a Union Carbide plant, a faulty valve allowed 1 ton of water for cleaning internal pipes to mix with 40 tons of methyl isocyanate. ${ }^{47}$ Pressure and heat from the reaction in the tank continued to build. As a safety valve

\begin{tabular}{|lll|}
\hline \multicolumn{2}{l}{$\begin{array}{l}\text { Table } 1 \\
\text { Predicting radiation-dose exposure by using time to onset of vomiting }\end{array}$} \\
\begin{tabular}{lll} 
Time from Exposure to Onset of Vomiting & Estimated Dose & Predicted Mortality \\
\hline$<10 \mathrm{~min}$ & $>8 \mathrm{~Gy}$ & $100 \%$ \\
\hline $10-30 \mathrm{~min}$ & $6-8 \mathrm{~Gy}$ & $100 \%$ \\
\hline $31-59 \mathrm{~min}$ & $4-6 \mathrm{~Gy}$ & $100 \%$ \\
\hline $1-2 \mathrm{~h}$ & $2-4 \mathrm{~Gy}$ & $>50 \%$ \\
\hline$>2 \mathrm{~h}$ & $<2 \mathrm{~Gy}$ & $>50 \%$ \\
\hline
\end{tabular}
\end{tabular}

Adapted from Radiation Emergency Assistance Center - Training site (REACTS) and International Atomic Energy Agency (IAEA). (Other sources quote different times, but trend is similar.) 
gave way, a plume of methyl isocyanate gas escaped, killing around 4000 people immediately. ${ }^{47}$ The injured soon overwhelmed the local hospitals, a crisis deepened by a lack of knowledge of exactly what gas was involved. ${ }^{47}$

The number of people killed in the first few days are estimated at $10,000 .{ }^{47}$ At least $200,000^{48}$ and, according to some reports, more than 500,000 people were exposed to the gas. These data are, however, likely to underrepresent the true extent of adverse events as many exposed individuals left Bhopal immediately following the disaster and were lost to follow-up. ${ }^{47}$

\section{Relevance to Today and Clinical Teaching Points}

These mass casualty incidents pose an overwhelming demand on hospital resources because of the need to decontaminate and manage a large number of critically ill patients. Following the initial release of methyl isocyanate, an estimated 200,000 people sought medical care. ${ }^{49}$ The city had four major hospitals but there was a shortage of physicians and hospital beds and no mass casualty emergency response system was in place in the city. ${ }^{49}$

The greatest numbers of patients seeking care in such disasters are often those who perceive they have been poisoned, but do not exhibit obvious signs or symptoms of poisoning. ${ }^{50}$ Many of these patients may have no exposure, and are merely worried. ${ }^{51}$ Demands from these anxious people decrease the ability of the medical system to effectively triage and identify the most critically ill patients. ${ }^{49}$ This event can be circumvented by planning for treatment of thousands of patients at the same time. ${ }^{52}$

This event in Bhopal dramatically highlighted the threat to the first responder, as was proven later in the sarin incident in Tokyo where almost $10 \%$ of the 1364 first responders sustained injured. ${ }^{53}$ These injuries to first responders were related to inadequate training and preparation. ${ }^{54}$

The events in Bhopal revealed the disastrous consequences of expanding industrialization in developing countries without simultaneous investment in safety regulations. ${ }^{55}$ Accidents involving hazardous toxic materials are predicted to occur predominantly in developing countries. ${ }^{56}$ However, the sarin poisoning incident in Japan revealed that developed nations may be equally vulnerable. ${ }^{57}$

The danger to communities from hazardous materials accidents is continuously on the rise. Of the 70,000 chemicals used industrially in the United Kingdom, more than 2000 are considered harmful and 200,000 tons are transported daily. ${ }^{50}$ In the United States, 15 events of gas release exceeding the Bhopal incident in quantity and toxicity occurred during the $1980 \mathrm{~s}^{49}$ Over 80,000 chemical agents commonly produced, transported, or used in the United States are toxic enough to rapidly produce lifethreatening conditions. ${ }^{49}$ Even so, a survey conducted in 2003 revealed gross underpreparation. ${ }^{58}$ With the heightened threat of deliberate offensive use of chemical warfare agents, it is imperative that hospitals be adequately prepared to handle such large-scale disasters ${ }^{59}$ through an effective response strategy, ${ }^{60}$ drawn on basic toxicologic principles. ${ }^{49}$

\section{Lessons for Critical Care}

- A mass casualty incident involving a toxic plume of gas may generate a significant number of casualties with impending or actual acute respiratory failure.

- Do you know if there is a hazardous materials route through your region/city/town that carries these sorts of materials? Do you currently have a critical care-specific triage plan that includes the procurement and allocation of mechanical ventilators? ${ }^{61}$ 
- Do you have an education plan in place that instructs critical care personnel in self-protection from contamination ${ }^{50,62}$

- A lot can be learned from the evolution of the chemical disaster response system in Japan over the last decade. ${ }^{57}$

- Rescue workers and medical personnel must be trained to operate under the threat of chemical contamination. ${ }^{52}$

\section{EVENT: OKLAHOMA CITY BOMBING}

Summary

On April 19, 1995, a truck carrying a mixture of ammonium nitrate fertilizer, nitro methane, and diesel fuel exploded near the Alfred P. Murrah Federal Building in downtown Oklahoma City, Oklahoma. This terrorist attack destroyed one third of that building and damaged numerous other buildings in a 16-block radius. Of the 361 persons who were in the federal building, 319 were injured, of whom 163 died, including 19 children. The most frequent cause of death was multiple injuries. Among survivors, musculoskeletal and head injuries were most common. ${ }^{63}$

\section{Relevance to Today and Clinical Teaching Points}

The most important lesson learned from the events of Oklahoma was that terrorists could wage their war on American soil. ${ }^{54}$

The second most important lesson-and one that is more sobering - is how easily explosives can be assembled. The bomb used by the Oklahoma bombers was primitive and assembled from easily available material.

Members of the hospital staffs at the receiving hospitals, such as the Columbia Presbyterian Hospital, have written of the valuable lessons about managing a sudden increase in activity, equipment and supplies, and staffing resources. ${ }^{64}$ One of the most significant problems was maintaining adequate communications. Even the hospital emergency administrative radio system was operational in only 3 of the 15 hospitals that handled patients. ${ }^{65}$ We need to have alternative back-up plans tested and in place now, before any event.

We also learned that structural collapse is the most important risk factor for fatality in a building bombing. Better building designs might make structural collapse less likely. Evacuation drills might reduce potential fatalities. ${ }^{66}$

\section{Lessons for Critical Care}

- Do you have a communications plan in place that will allow you to mobilize and augment critical staffing on extremely short notice? Can this plan be executed if usual telephone (including cell phone) access is overloaded?

- Posttraumatic stress disorder in health care workers is significant and must be treated early and effectively. ${ }^{67}$

- This does not require terrorists to make these a reality... what about a large-scale conventional explosion at a factory? Are you ready? Does your ICU have a plan?

\section{EVENT: SEPTEMBER 11, 2001}

\section{Summary}

On September 11, 2001, terrorists hijacked four passenger planes and crashed two of these planes against the World Trade Center towers in New York City. ${ }^{68}$ This was the largest terrorist attack ever on United States soil. At the time, approximately 60,000 people worked and an estimated 90,000 more people visited the buildings each day. A total of 2726 persons were killed. ${ }^{68}$ In Washington, D.C., a hijacked jet was 
flown into the Pentagon building. The crash and fire killed almost 200 people and injured an additional $500 .^{69}$

\section{Relevance to Today and Clinical Teaching Points}

\section{Preparedness}

The city of New York was prepared adequately at multiple levels. St. Vincent's Hospital was one of the main receiving hospitals and performed well to avoid over-triage ${ }^{70}$ and kept a balance between early treatment of the critically ill patients while catering to a large number of minimally injured patients. ${ }^{71}$ The most important factor in enhancing the hospital's preparedness for this event was the prior involvement in caring for the 1993 World Trade Center bombing victims. As a result of that event, the hospital had developed a more detailed disaster plan and conducted a series of drills.

At the city level, New York had the Metropolitan Medical Response System, a welldeveloped system that made for smooth coordination with regional response networks and quick distribution of the National Emergency Stockpile assets. ${ }^{54}$

\section{Lateral thinking}

However, there were instances of flawed communications and inefficient sharing of information in the wake of the September 11 tragedy. ${ }^{72}$ These problems stemmed from the vertical hold some agencies and organizations had on decision-making capacity. ${ }^{73}$ All large-scale mass casualty events require decision-making capacities that are lateral in nature as no one organization has the expertise needed to make all vital decisions. ${ }^{74}$

\section{Poor awareness of secondary contamination}

A number of health care providers were sent to Ground Zero without taking precautions for possible involvement of nuclear, biologic, or chemical weapons, or even for the toxic productions of combustion. This put them at great risk for significant illness. $^{71}$

\section{Logistical problems}

Several logistic problems made an impact on treatment efforts. Within hours of the disaster, electricity and phone services were lost, cellular communications were not operative, and computer communication lines failed. The use of two-way radios by key hospital personnel served to minimize the disruption in intrahospital communications. ${ }^{71}$ These problems illustrate the need for systems that simultaneously use several communication alternatives, all of which may be deployed on handheld computers. ${ }^{75}$

\section{Lessons for Critical Care}

- Even though the September 11 attack involved conventional explosives, critical care specialists must be prepared to deal with contaminated casualties as a secondary complication. ${ }^{76}$

- Communications, communications, communications...

- Clinical volunteers may not be who they claim to be. Credentials must be verified.

- We are critical care specialists, not first responders. We are not trained to recognize danger at the incident site (eg, live electrical wires, unstable building structures, toxic substances). Stay in the hospital.

- Doctors can be trained in such skills as extrication, triage, and transport. ${ }^{77}$

- Hospitals are only a small part of an overall disaster response plan. The primary function of an incident response plan is not only to evacuate casualties, but also to protect the uninjured. 


\section{EVENT: OUTBREAK OF SEVERE ACUTE RESPIRATORY SYNDROME}

\section{Summary}

In 2003, an infectious disease outbreak began in China. Initially involving animal-to-human transmission of a coronavirus that caused a severe and even fatal acute respiratory illness, this outbreak originated with food handlers in the "wet" markets of Southern China, rapidly spread to Hong Kong, to other parts of Asia, and then to other parts of the world over the ensuing weeks to months. ${ }^{78}$ The rapid worldwide transmission of this disease reflects our current global mobility via commercial air travel. ${ }^{79} \mathrm{Ul}-$ timately, SARS killed approximately 800 people and infected over 8000 others in almost 30 countries on every continent.

\section{Relevance to Today and Clinical Teaching Points}

Notably, a startlingly high percentage of the patients were health care workers. ${ }^{80}$ These cases illustrated how insufficient infection control practices can be lethal And also raised important questions about how people react to such an outbreak: Who will show up for work in the hospital? How will people respond if their workplace (ie, the ICU) significantly places them at risk for contracting a life-threatening illness? ${ }^{81}$

The SARS epidemic has better prepared the world's public health authorities for a major influenza or other pandemic. ${ }^{81}$ While there are differences, many of these same issues are applicable to pandemic influenza or a bioterrorism event. ${ }^{82}$ In fact, many authorities remain concerned that a pandemic influenza outbreak (such as an avian influenza outbreak) would be orders of magnitude greater in scope than SARS and the goal to minimize damage from such an event has become a global health priority. ${ }^{83}$ Therefore, infection control and other preventative measures are of major importance, ${ }^{84}$ but so will be triage and allocation of mechanical ventilators and other life-support measures. ${ }^{85}$

Furthermore, education and training of ICU personnel in the assiduous practices of self-protective measures will also be key to ensuring that absenteeism does not become a problem (ie, not coming to work because of concerns related to contracting the disease). ${ }^{86}$ Finally, no plan equals chaos. To ensure that the appropriate education and training occur, and to establish effective triage strategies/algorithms for your hospital, ${ }^{87}$ advance work to achieve leadership consensus should happen now, not after a disaster begins.

One of the key lessons is that we are vulnerable to events far away. ${ }^{81}$

\section{Lessons for Critical Care}

- What percent of your ICU personnel are current for fit-testing of N-95\% masks? If your hospital is typical, that number is perhaps $50 \%$. And if we can keep up with this simple requirement, then what of more advanced vital skills, like flawless (error-free) donning and doffing of personal protective equipment? ${ }^{88}$

- Do you have a ventilator triage plan? ${ }^{89}$

- Do you have a pandemic influenza plan that includes your ICU ${ }^{90}$ Does it work? Has it been exercised or practiced in some measurable capacity?

- Do you have a plan to prevent bronchoscope-associated infection ${ }^{91}$

\section{EVENT:TSUNAMI}

\section{Summary}

On December 26, 2004, an earthquake beneath the Indian Ocean triggered a large tsunami that struck in Indonesia, Sri Lanka, India, Somalia, and Thailand. ${ }^{92}$ This 9.2magnitude earthquake and the ensuing tsunami led to the death of an estimated 
225,000 people in at least 11 countries and the displacement of over 1 million people. In terms of deaths and population displacement, this tsunami was among the most devastating in human history. Between $30 \%$ and $40 \%$ of the total number killed were children. The medical infrastructure in most of the coastal region was destroyed in these countries, ${ }^{93}$ and there was no secure (uncontaminated) water source. ${ }^{92}$ Consequently, many people had little or no access to medical care for trauma injuries, infections, and subsequent public health-related outbreaks, such as cholera and malaria. ${ }^{94}$ There were also very high rates of posttraumatic stress disorder among survivors. ${ }^{95}$

\section{Relevance to Today and Clinical Teaching Points}

The clinical teaching points from the tsunami disaster were best described by Claude de Ville de Goyet, MD, ${ }^{93}$ retired director of the Emergency Preparedness Program of the Pan-American Health Organization (PAHO), and others ${ }^{96}$ in detail. One of the essential flaws was a gaping gulf between the needs of the local communities as they perceived them and the needs assessment performed by the aiding agencies. ${ }^{93}$ World response to the event included over $\$ 13$ billion in aid. ${ }^{93}$ However, many donations from industrialized countries included aid items that were not germane to postdisaster needs of casualties. Nevertheless, these items required the same logistical support to unload or store, thus redirecting time and energy away from important relief efforts to things that were not as helpful. ${ }^{97} \mathrm{~A}$ hasty response that is not based on familiarity with local conditions contributes to more chaos. It is prudent to wait until real needs have been assessed. ${ }^{98}$

False alarms were raised about the probability of more deaths from secondary epidemics than from the tsunami itself. ${ }^{93}$ These "overly alarmist announcements" related to problems that did not materialize provide valuable lessons in appropriate and responsible disaster communication.

Foreign mobile hospitals rarely arrived in time for immediate trauma care, leaving local, sometimes damaged facilities to provide immediate, life-saving care. ${ }^{93}$ In many instances, immediate assistance to the injured was provided by uninjured survivors with whatever basic first aid they knew without any tools or resuscitation equipment. ${ }^{99}$ This experience supports proposals for teaching life-supporting first aid courses to the public. ${ }^{100}$

A lot has been written about the dynamics of assistance during disasters. In general, however, as depicted in Fig. 1, human nature dictates an initial outpouring of generosity as attention focuses on the first news of the disaster. This widespread generosity falls off quickly over time, leaving committed responders behind to carry the burden of responsibility for aid. The response to the tsunami followed this pattern.

\section{Lessons for Critical Care}

- History keeps repeating itself: In the wake of a large-scale disaster that creates an austere care environment, systems are needed for rapidly deploying portable, sophisticated care, but such systems are rarely in place.

- Critical care doctors must be prepared to perform in surroundings with suboptimal public health structure in the wake of a disaster. ${ }^{101,102}$

- Flexibility to adapt to local circumstances and fit in the local incident command system is essential for doctors helping in foreign disasters. ${ }^{93}$ 


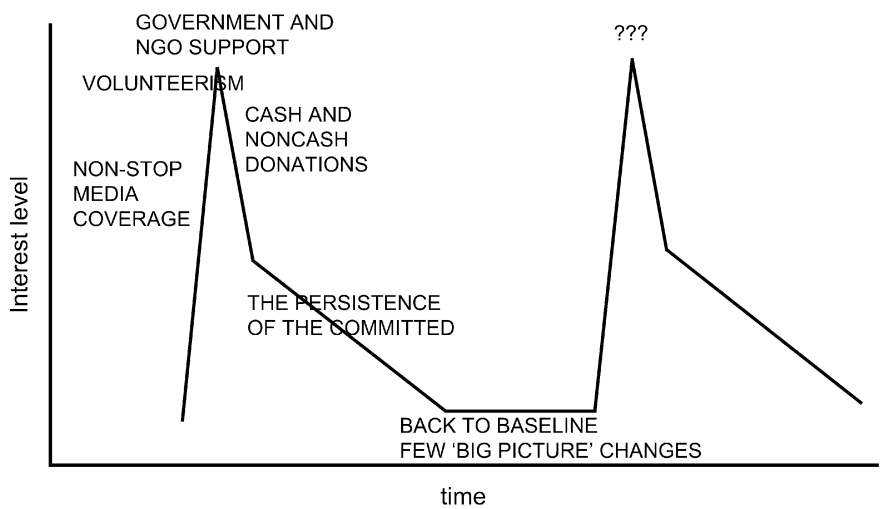

Fig.1. Rise and fall over time of desire to "help" with disaster relief, NGO, nongovernmental organization.

\section{EVENT: HURRICANE KATRINA}

\section{Summary}

In August 2005, Hurricane Katrina caused the rupture of levees protecting New Orleans, Louisiana, leading to devastating flooding and the destruction of much of the city's infrastructure. This resulted in a public health emergency that displaced more than 4400 physicians in the greater New Orleans area and led to the closure of 13 of 16 hospitals. This caused widespread destruction, reducing hospital capacity by $80 \%$ and clinic capacity by $75 \%$ in New Orleans. ${ }^{103}$

\section{Relevance to Today and Clinical Teaching Points}

As we look at the big picture, it appears that the poor outcome in this disaster was not the result of lack of knowledge, but rather the result of inaction ${ }^{103}$ and poor implementation ${ }^{104}$ of the necessary measures. ${ }^{105}$

We witnessed the impact of a complete loss of critical care capability on the general population. Specifically, there were numerous secondary casualties-patients with chronic critical illnesses who lost access to care rapidly became ill. ${ }^{106}$ These patients consumed a significant amount of the available rescue medical care. ${ }^{107}$

A number of lessons pertinent to critical care were (re)learned at a very high cost. ${ }^{108}$ The foremost was how much the delivery of critical care services depends on support services, such as water and electricity. The worst hit hospital in New Orleans was Charity Hospital. Rising floodwaters submerged the hospital's emergency electrical generators. This left no reliable electrical power for life-support systems, such as mechanical ventilators, suction machines, bedside monitors, intravenous fluid pumps, and dialysis machines. Even air conditioning was lost. ${ }^{109}$ Radiology and laboratory capability became extinct. Patients who required positive-pressure ventilation had to be hand ventilated with bag-valve devices in total darkness. 6

\section{Lesson in evacuation surge capacity}

Many hospitals were incapacitated simultaneously. ${ }^{110}$ This left the option to either deploy field hospitals or to evacuate. Unfortunately, portable critical care exists only at certain facilities and is generally not developed as a deployable asset. Therefore, all hospitals in general and especially those located in regions subject to hurricanes and earthquakes should make extraordinary investments to develop coalition partners 
and to ensure portability of sophisticated care. ${ }^{111}$ A reasonable solution would be collaboration across regions to enable long-distance patient and staff transfer during emergencies. ${ }^{112}$ Adequate knowledge of the operational status of surrounding facilities expedites such transfer. The Department of Health and Human Services Critical Infrastructure Data System was employed to track the local, state, and national availability of medical care for hurricane victims following Hurricane Rita in 2005. A means of rapidly assessing the needs of the affected area would allow proper resource deployment and use. ${ }^{113}$

\section{Field hospitals}

Significant experience was gained in the deployment and management of field hospitals. A prominent example is the Carolinas Med-1. ${ }^{114}$ This mobile hospital consisted of two 53-ft tractor-trailers. One served as an equipment storage unit and the other as the patient care facility. ${ }^{114}$ Up to 130 beds, including emergency room beds, ICU beds, and surgical suites, could be accommodated. It also provided diagnostic radiology and point-of-care laboratory services. During the 6-week deployment, more than 7400 patients were evaluated and treated at this mobile facility by integrating seamlessly into the existing local, state, and federal facilities. ${ }^{114}$

\section{Staffing issues}

Out-of-state physician volunteers who responded to this were practicing medicine without a license, potentially placing them at risk for penalties. Louisiana Governor Kathleen Blanco issued an executive order that suspended regular licensing procedures. However, the policies of each state regarding physician licensure during disasters ought to be determined. ${ }^{115}$

\section{Lessons for Critical Care}

- What happens if you suffer a power outage in your ICU, and the generators fail to work? It happens...sometimes even without a natural disaster ${ }^{5,116}$

- If you had to completely evacuate your ICU out of the building, including even the sickest patients, could you do it safely? ${ }^{117}$ How? Where would you go? What is the plan? ${ }^{118}$

- Under extreme circumstances, would you come to work ${ }^{119}$ Think about it...

- Do you have a plan for regional cooperation between hospitals and ICUs? ${ }^{120}$ Have you ever conducted an exercise around this premise? ${ }^{111}$

- Chronic illnesses will coexist and may aggravate management of acute illness. ${ }^{121-123}$

- Responsible crisis communication is essential to prevent avoidable secondary complications. ${ }^{124}$

\section{EVENT: OPERATION IRAQI FREEDOM AND OPERATION ENDURING FREEDOM}

\section{Summary}

Operation Enduring Freedom (OEF) was the coordinated military operation that started in October 2001 in Afghanistan to oust the Taliban from power. In Operation Iraqi Freedom (OIF), the United States-led coalition forces entered into armed conflict with Iraq on March 19, 2003, and by May 1, 2003, active hostilities were declared over. ${ }^{125}$ According to the US Department of Defense online data of American military casualties (the number of wounded or dead) from OIF/OEF, the operations led to the deaths of 4733 American servicemen as of September 3, 2008. ${ }^{126}$

Traditional battlefield medicine has focused on providing "definitive" trauma casualty care within the theater of operations. Injured soldiers were then transported back 
to their home country when they became "stable." This translated to 15 to 45 days intheater before evacuation to hospitals in their home countries. In addition, because moving unstable casualties (who now require advanced ICU care) rearward after surgery is so difficult and unreliable, moving trauma surgical care closer to the point of injury was generally not done. So historically, casualties had to survive until they were evacuated back to an echelon where surgical care became available.

During these most recent conflicts in Iraq and Afghanistan, a concept of portable critical care has been employed with great success and has proven to be an advancement over the traditional methods of battlefield medicine. ${ }^{127,128} \mathrm{~A}$ casualty receives "damage control" (targeted, limited, life-saving) surgery as soon as possible after the injury and as close as possible to the battlefield location of injury. ${ }^{20}$ Then, critical care teams are used to evacuate these patients rearward. ${ }^{129}$ Along the way, subsequent additional "damage control" procedures may be required. Today, from time of injury a casualty is typically evacuated back to the United States within 72 to 96 hours, and may have had several incremental surgical procedures performed along the way..$^{130}$ This approach has resulted in the lowest died-of-wounds rate in the history of warfare. ${ }^{131}$

These critical care teams were developed and are maintained by the U.S. Air Force. They are part of the Critical Care Aeromedical Transport Team program. ${ }^{132}$ These teams are capable of providing all aspects of critical care, including advanced mechanical ventilatory support; invasive cardiovascular monitoring; pharmacologic support, diagnosis, and treatment of sepsis or other forms of shock; limited laboratory assessment; portable ultrasound; portable bronchoscopy; and even extracorporeal support in limited circumstances. ${ }^{133}$ Much of this occurs in austere settings, such as the back of an Air Force cargo plane during flights from the Middle East to Germany, and again across the Atlantic Ocean. ${ }^{134,135}$

\section{Relevance to Today and Clinical Teaching Points}

Provision of critical care in a transport setting imposes unique challenges, particularly when the duration of patient transfer is prolonged. ${ }^{9,136}$ As a simple example, monitoring technologies must overcome limitations imposed by noise. Automated blood pressure monitors, measurement of oxygen saturation, and end-tidal carbon dioxide with limited electrocardiography may represent the only available cardiopulmonary monitoring. Ventilators must offer a range of tidal volumes, but a limited number of modes may be available. Variable minute ventilation must be provided over a wide range of barometric pressure conditions. Infusion devices must be compact and robust with extended battery life and pressure-activated occlusion alarms. Only point-of-care laboratory testing may be available in remote settings and in the transport environment. Finally, a limited drug list must be developed to include provision for analgesia and sedation, and to accommodate the need for vasoconstriction, inotropic support, or vasodilatation with various shock states.

Beyond its use by the Critical Care Aeromedical Transport Team, this approach to critical care may be adapted for a significant potential role in disaster response medicine. An aeromedical transport system adapted for civilian use could go a long way toward addressing many of the issues raised in this article, including (1) the transport of ICU patients when a hospital is rendered unusable or the number of critically ill or injured casualties exceeds local/regional capability, (2) a surge of patients with chronic critical illnesses who lose access to ongoing support following a disaster (and who significantly tax other disaster-response assets), and (3) the overall need to extend critical care capability within the disaster response locale (eg, expanding hospital ICU capability to non-ICU areas of the facility). 


\section{Lessons for Critical Care}

- "Portable" critical care is a necessary component of any robust disaster medical response capability. Without this, we do not have an effective answer for the needs articulated in this article.

- Interagency collaboration and communication assumes even greater importance during complex humanitarian emergencies, such as wars. ${ }^{125}$

- Opportunities for collaboration exist between military and civilian response systems to translate shared expertise into benefits for all critically ill patients, whether in a roadside accident or on the battlefield. ${ }^{25}$

\section{SUMMARY}

This effort represents our attempts to review a cross-section of representative disasters that illustrate recurring, important themes related to critical care and hospital disaster response. It is by no means comprehensive; unfortunately disasters that impact large numbers of patients, and require critical care resources occur commonly. We selected disasters for discussions that illustrate core principles relevant to critical care practitioners. To summarize these "lessons learned" include:

1. Disaster preparation typically focuses all pre-hospital care requirements, and often neglects the needs of the hospital, and especially intensive care units. This impacts ICU response in several ways including sufficiency of space, equipment and supplies, triage protocols, and so forth.

2. A burgeoning number of non-hospitalized individuals with chronic critical illness. When a disaster occurs that limits access to advanced medical care, these patients rapidly decompensate, and in many circumstances utilize/consume more disaster response resources than primary casualties.

3. Following a disaster, existing critical care resources may be insufficient to meet demand for services. Developing a deliberate plan (5) that pre-identifies alternative care sites for ICU patients is essential. This must include access to sufficient quantities of 50 psi oxygen, suctioning, medical devices, and necessary pharmacy support.

4. Following a disaster of sufficient magnitude, non-critical care hospital personnel will be called to assist with the care of ICU patients. It is important to know, in advance what will be the scope of practice of these individuals, what education is needed to ensure that this care is efficient and of reliable quality, and who will provide supervision and assistance for these activities.

5. Following a disaster, it is vitally important to ensure the protection of ICU personnel from communicable diseases/outbreaks, as well as physical harm. This requires a plan, practice, and proper education of staff.

6. When a large scale disaster occurs, medical care processes quickly migrate below usual standards of care due to resource limitations. This degradation of care should be planned and not haphazard. This can also be pre-planned as it relates to access to mechanical ventilation, staffing ratios, aggressiveness of resuscitation based on probability of survival, etc. The goal is to predictably orchestrate transition from "standard of care" to "sufficiency of care."

Except for individuals who volunteer their time or who are engaged in disaster preparedness, there is generally a limited willingness by health care professionals to accept that these concerns as relevant to their daily professional lives. Furthermore, in a cost-constrained hospital, these low probability but high consequence needs 
do not compete favorably with more tangible, other needs (eg, purchasing a new CT scanner).

\section{But as with everything else ... \\ Those who cannot learn from history are doomed to repeat it.}

- George Santayana.

\section{REFERENCES}

1. Avendano M, Derkach $P$, Swan S. Clinical course and management of SARS in health care workers in Toronto: a case series. CMAJ 2003;168(13):1649-60.

2. Scales DC, Green K, Chan AK, et al. Illness in intensive care staff after brief exposure to severe acute respiratory syndrome. Emerg Infect Dis 2003;9(10): 1205-10.

3. Fowler RA, Guest CB, Lapinsky SE, et al. Transmission of severe acute respiratory syndrome during intubation and mechanical ventilation. Am J Respir Crit Care Med 2004;169(11):1198-202.

4. Gautschi OP, Cadosch D, Rajan G, et al. Earthquakes and trauma: review of triage and injury-specific, immediate care. Prehospital Disaster Med 2008;23(2): 195-201.

5. Dr Okie S. Pou and the hurricane-implications for patient care during disasters. N Engl J Med 2008;358(1):1-5.

6. deBoisblanc BP. Black Hawk, please come down: reflections on a hospital's struggle to survive in the wake of Hurricane Katrina. Am J Respir Crit Care Med 2005;172(10):1239-40.

7. Myae K. Six days in the delta. CMAJ 2008;179(1):30.

8. Chan EYT. The untold story of the Sichvan earthquake. The Lancet 2008;372: 359-62.

9. Grissom TE, Farmer JC. The provision of sophisticated critical care beyond the hospital: lessons from physiology and military experiences that apply to civil disaster medical response. Crit Care Med 2005;33(1 Suppl):S13-21.

10. Dara SI, Ashton RW, Farmer JC, et al. Worldwide disaster medical response: an historical perspective. Crit Care Med 2005;33(1 Suppl):S2-6.

11. Noji EK. Disasters: introduction and state of the art. Epidemiol Rev 2005;27:3-8.

12. Dara SI, Ashton RW, Farmer JC. Engendering enthusiasm for sustainable disaster critical care response: Why this is of consequence to critical care professionals? Crit Care. 2005;9(2):125-7.

13. Pou AM. Hurricane Katrina and disaster preparedness. N Engl J Med 2008; 358(14): 1524.

14. Noji EK. Creating a health care agenda for the Department of Homeland Security. Manag Care 2003;12(11 Suppl):7-12.

15. Michael WS, Julia AM. Chemical-biological terrorism and its impact on children. Pediatrics 2006;118(3):1267-78.

16. About FEMA. Available at: http://www.fema.gov/about/index.shtm. Accessed September 6, 2008.

17. Handler JA, Gillam M, Kirsch TD, et al. Metrics in the science of surge. Acad Emerg Med 2006;13(11):1173-8.

18. Kanter RK, Moran JR. Pediatric hospital and intensive care unit capacity in regional disasters: expanding capacity by altering standards of care. Pediatrics 2007;119(1):94-100.

19. Ksiazek TG, Erdman D, Goldsmith CS, et al. A novel coronavirus associated with severe acute respiratory syndrome. N Engl J Med 2003;348(20):1953-66. 
20. Blackbourne LH. Combat damage control surgery. Crit Care Med 2008; 36(Suppl 7):S304-10.

21. Beekley AC. Damage control resuscitation: a sensible approach to the exsanguinating surgical patient. Crit Care Med 2008;36(7 Suppl):S267-74.

22. Birnbaum ML. Times have changed. Prehospital Disaster Med 2003;18(4):276-7.

23. Frykberg ER. Disaster and mass casualty management: a commentary on the American College of Surgeons position statement. J Am Coll Surg 2003; 197(5):857-9.

24. Waeckerle JF, Seamans S, Whiteside M, et al. Executive summary: developing objectives, content, and competencies for the training of emergency medical technicians, emergency physicians, and emergency nurses to care for casualties resulting from nuclear, biological, or chemical incidents. Ann Emerg Med 2001;37(6):587-601.

25. Moore EE, Knudson MM, Schwab CW, et al. Military-civilian collaboration in trauma care and the senior visiting surgeon program. N Engl J Med 2007; 357(26):2723-7.

26. Collins ST. Emergency medical support units to critical care transport teams in Iraq. Crit Care Nurs Clin North Am 2008;20(1):1-11, v.

27. Carlton PK Jr, Jenkins DH. The mobile patient. Crit Care Med 2008;36(7 Suppl): S255-7.

28. Grathwohl KW, Venticinque SG, Blackbourne LH, et al. The evolution of military trauma and critical care medicine: applications for civilian medical care systems. Crit Care Med 2008;36(Suppl 7):S253-4.

29. Drosten C, Gunther S, Preiser W, et al. Identification of a novel coronavirus in patients with severe acute respiratory syndrome. N Engl J Med 2003;348(20): 1967-76.

30. Teich JM, Wagner MM, Mackenzie CF, et al. The informatics response in disaster, terrorism, and war. J Am Med Inform Assoc 2002;9(2):97-104.

31. Auf der Heide E. The importance of evidence-based disaster planning. Ann Emerg Med 2006;47(1):34-49.

32. Baker MS. Creating order from chaos: part I: triage, initial care, and tactical considerations in mass casualty and disaster response. Mil Med 2007;172(3): 232-6.

33. Seynaeve G, Archer F, Fisher J, et al. International standards and guidelines on education and training for the multi-disciplinary health response to major events that threaten the health status of a community. Prehospital Disaster Med 2004; 19(2):S17-30.

34. Farmer JC. Respiratory issues in aeromedical patient transport. Respir Care Clin N Am 1996;2(3):391-400.

35. Szalados JE. Critical care teams managing floor patients: the continuing evolution of hospitals into intensive care units? [comment]. Crit Care Med 2004;32(4): 1071-2.

36. Kvetan V. Intensive care in a field hospital in an urban disaster area: Are we ready? Crit Care Med 2003;31(5):1589-90.

37. Hick JL, Hanfling D, Burstein JL, et al. Health care facility and community strategies for patient care surge capacity. Ann Emerg Med 2004;44(3):253-61.

38. Hatch M, Ron E, Bouville A, et al. The Chernobyl disaster: cancer following the accident at the Chernobyl nuclear power plant. Epidemiol Rev 2005;27:56-66.

39. Rahu M. Health effects of the Chernobyl accident: fears, rumours and the truth. Eur J Cancer 2003;39(3):295-9.

40. Radiation disasters and children. Pediatrics 2003;111(6 Pt 1):1455-66. 
41. Turai I, Veress K, Gunalp B, et al. Medical response to radiation incidents and radionuclear threats [see comment]. BMJ 2004;328(7439):568-72.

42. Bar Joseph N, Reisfeld D, Tirosh E, et al. Neurobehavioral and cognitive performances of children exposed to low-dose radiation in the Chernobyl accident: the Israeli Chernobyl Health Effects Study. Am J Epidemiol 2004;160(5):453-9.

43. Mettler FA Jr, Voelz GL. Major radiation exposure-what to expect and how to respond. N Engl J Med 2002;346(20):1554-61.

44. Burnham JW, Franco J. Radiation. Crit Care Clin 2005;21(4):785-813, vii-viii.

45. Koenig KL, Goans RE, Hatchett RJ, et al. Medical treatment of radiological casualties: current concepts. Ann Emerg Med 2005;45(6):643-52.

46. Hammond J, Brooks J. The World Trade Center attack. Helping the helpers: the role of critical incident stress management. Crit Care 2001;5(6):315-7.

47. Broughton E. The Bhopal disaster and its aftermath: a review. Environ Health 2005;4(1):6.

48. Ranjan N, Sarangi S, Padmanabhan VT, et al. Methyl isocyanate exposure and growth patterns of adolescents in Bhopal. JAMA 2003;290(14):1856-7.

49. Kirk MA, Deaton ML. Bringing order out of chaos: effective strategies for medical response to mass chemical exposure. Emerg Med Clin North Am 2007;25(2): 527-48 [Abstract xi].

50. Clarke SF, Chilcott RP, Wilson JC, et al. Decontamination of multiple casualties who are chemically contaminated: a challenge for acute hospitals. Prehospital Disaster Med 2008;23(2):175-81.

51. Baker DJ. Critical care requirements after mass toxic agent release. Crit Care Med 2005;33(1 Suppl):S66-74.

52. Lorin HG, Kulling PE. The Bhopal tragedy —What has Swedish disaster medicine planning learned from it? J Emerg Med 1986;4(4):311-6.

53. Tucker JB. National health and medical services response to incidents of chemical and biological terrorism. JAMA 1997;278(5):362-8.

54. Johannigman JA. Disaster preparedness: It's all about me. Crit Care Med 2005; 33(1 Suppl):S22-8.

55. Varma R, Varma DR. The Bhopal disaster of 1984. Bull Sci Technol Soc 2005; 25(1):37-45.

56. Arnold JL. Disaster medicine in the 21 st century: future hazards, vulnerabilities, and risk. Prehospital Disaster Med 2002;17(1):3-11.

57. Okumura T, Ninomiya N, Ohta M. The chemical disaster response system in Japan. Prehospital Disaster Med 2003;18(3):189-92.

58. Keim ME, Pesik N, Twum-Danso NA. Lack of hospital preparedness for chemical terrorism in a major US city: 1996-2000. Prehospital Disaster Med 2003;18(3):193-9.

59. Tur-Kaspa I, Lev EI, Hendler I, et al. Preparing hospitals for toxicological mass casualties events. Crit Care Med 1999;27(5):1004-8.

60. Farmer JC, Carlton PK Jr. Who is 9-1-1 to the 9-1-1? Crit Care Med 2002;30(10): 2397-8.

61. Devereaux AV, Dichter JR, Christian MD, et al. Definitive care for the critically ill during a disaster: a framework for allocation of scarce resources in mass critical care: from a Task Force for Mass Critical Care summit meeting, January 26-27, 2007, Chicago, IL. Chest 2008;133(5 Suppl):51S-66S.

62. Okumura S, Okumura T, Ishimatsu S, et al. Clinical review: Tokyo_-protecting the health care worker during a chemical mass casualty event: an important issue of continuing relevance. Crit Care 2005;9(4):397-400.

63. Mallonee S, Shariat S, Stennies G, et al. Physical injuries and fatalities resulting from the Oklahoma City bombing. JAMA 1996;276(5):382-7. 
64. Anteau CM, Williams LA. The Oklahoma bombing. Lessons learned. Crit Care Nurs Clin North Am 1997;9(2):231-6.

65. Maningas PA, Robison M, Mallonee S. The EMS response to the Oklahoma City bombing. Prehospital Disaster Med 1997;12(2):80-5.

66. Glenshaw MT, Vernick JS, Li G, et al. Preventing fatalities in building bombings: What can we learn from the Oklahoma City bombing? Disaster Med Public Health Prep 2007;1(1):27-31.

67. Rhoads J, Pearman T, Rick S. PTSD: therapeutic interventions post-Katrina. Crit Care Nurs Clin North Am 2008;20(1):73-81, vii.

68. Cruz MA, Burger R, Keim M. The first 24 hours of the World Trade Center attacks of 2001-the Centers for Disease Control and Prevention emergency phase response. Prehospital Disaster Med 2007;22(6):473-7.

69. Wang D, Sava J, Sample G, et al. The Pentagon and 9/11. Crit Care Med 2005; 33(1 Suppl):S42-7.

70. Roccaforte JD, Cushman JG. Disaster preparedness, triage, and surge capacity for hospital definitive care areas: optimizing outcomes when demands exceed resources. Anesthesiol Clin 2007;25(1):161-77, xi.

71. Kirschenbaum L, Keene A, O'Neill P, et al. The experience at St. Vincent's Hospital, Manhattan, on September 11, 2001: preparedness, response, and lessons learned. Crit Care Med 2005;33(1 Suppl):S48-52.

72. Roccaforte JD. The World Trade Center attack. Observations from New York's Bellevue Hospital. Crit Care 2001;5(6):307-9.

73. Burkle FM Jr. Integrating international responses to complex emergencies, unconventional war, and terrorism. Crit Care Med 2005;33(1 Suppl):S7-12.

74. Burkle FM Jr, Hayden R. The concept of assisted management of large-scale disasters by horizontal organizations. Prehospital Disaster Med 2001;16(3): 128-37.

75. Grasso MA. Handheld computer application for medical disaster management. AMIA Annu Symp Proc 2006;932.

76. Shamir MY, Rivkind A, Weissman C, et al. Conventional terrorist bomb incidents and the intensive care unit. Curr Opin Crit Care 2005;11(6):580-4.

77. Ryan J, Montgomery $\mathrm{H}$. The London attacks_-preparedness: terrorism and the medical response. N Engl J Med 2005;353(6):543-5.

78. Weinstein RA. Planning for epidemics - the lessons of SARS. N Engl J Med 2004;350(23):2332-4.

79. Diaz JH. Global climate changes, natural disasters, and travel health risks. J Travel Med 2006;13(6):361-72.

80. Ho AS, Sung JJ, Chan-Yeung M. An outbreak of severe acute respiratory syndrome among hospital workers in a community hospital in Hong Kong. Ann Intern Med 2003;139(7):564-7.

81. Emanuel EJ. The lessons of SARS. Ann Intern Med 2003;139(7):589-91.

82. Varkey P, Poland GA, Cockerill FR 3rd, et al. Confronting bioterrorism: physicians on the front line. Mayo Clin Proc 2002;77(7):661-72.

83. Ferguson NM, Cummings DA, Fraser C, et al. Strategies for mitigating an influenza pandemic. Nature 2006;442(7101):448-52.

84. Gomersall CD, Joynt GM, Ho OM, et al. Transmission of SARS to healthcare workers. The experience of a Hong Kong ICU. Intensive Care Med 2006; 32(4):564-9.

85. Christian MD, Hawryluck L, Wax RS, et al. Development of a triage protocol for critical care during an influenza pandemic. CMAJ 2006;175(11):1377-81. 
86. Ruderman C, Tracy CS, Bensimon CM, et al. On pandemics and the duty to care: Whose duty? Who cares? BMC Med Ethics 2006;7:E5.

87. Challen K, Bentley A, Bright J, et al. Clinical review: mass casualty triage-pandemic influenza and critical care. Crit Care 2007;11(2):212.

88. Loutfy MR, Wallington T, Rutledge T, et al. Hospital preparedness and SARS. Emerg Infect Dis 2004;10(5):771-6.

89. Hick JL, O'Laughlin DT. Concept of operations for triage of mechanical ventilation in an epidemic. Acad Emerg Med 2006;13(2):223-9.

90. Gomersall CD, Loo S, Joynt GM, et al. Pandemic preparedness. Curr Opin Crit Care 2007;13(6):742-7.

91. Mehta AC, Prakash UB, Garland R, et al. American College of Chest Physicians and American Association for Bronchology [corrected] consensus statement: prevention of flexible bronchoscopy-associated infection. Chest 2005;128(3):1742-55.

92. Kohl PA, O'Rourke AP, Schmidman DL, et al. The Sumatra-Andaman earthquake and tsunami of 2004: the hazards, events, and damage. Prehospital Disaster Med 2005;20(6):355-63.

93. de Ville de Goyet $\mathrm{C}$. Health lessons learned from the recent earthquakes and tsunami in Asia. Prehospital Disaster Med 2007;22(1):15-21.

94. Cranmer $\mathrm{HH}$. The public health emergency in Indonesia-one patient at a time. N Engl J Med 2005;352(10):965.

95. Lamberg L. As tsunami recovery proceeds, experts ponder lessons for future disasters. JAMA 2005;294(8):889-90.

96. Kapila M, McGarry N, Emerson E, et al. Health aspects of the tsunami disaster in Asia. Prehospital Disaster Med 2005;20(6):368-77.

97. Kripalani M. India pulls together amid disaster 2005. Available at: http://meaindia. nic.in/bestoftheweb/2005/01/11bw01.htm. Accessed Sep 6, 2008.

98. de Ville de Goyet C. Stop propagating disaster myths. Lancet 2000;356(9231): 762-4.

99. Smith J, Fink S, Hansch S, et al. Session 1.4: health services delivery: a critical review of experience. Prehospital Disaster Med 2005;20(6):389-92.

100. Crippen D. The World Trade Center attack. Similarities to the 1988 earthquake in Armenia: time to teach the public life-supporting first aid? Crit Care 2001;5(6): 312-4.

101. Cranmer HH. Hurricane Katrina. Volunteer work-logistics first. N Engl J Med 2005;353(15):1541-4.

102. Noji EK. Public health in the aftermath of disasters. BMJ 2005;330(7504): 1379-81.

103. Lambrew JM, Shalala DE. Federal health policy response to Hurricane Katrina: What it was and what it could have been. JAMA 2006;296(11):1394-7.

104. Gheytanchi A, Joseph L, Gierlach E, et al. The dirty dozen: twelve failures of the Hurricane Katrina response and how psychology can help. Am Psychol 2007; 62(2):118-30.

105. Nates JL, Moyer VA. Lessons from Hurricane Katrina, tsunamis, and other disasters. Lancet 2005;366(9492):1144-6.

106. Kessler RC. Hurricane Katrina's impact on the care of survivors with chronic medical conditions. J Gen Intern Med 2007;22(9):1225-30.

107. Miller AC, Arquilla B. Chronic diseases and natural hazards: impact of disasters on diabetic, renal, and cardiac patients. Prehospital Disaster Med 2008;23(2):185-94.

108. Curiel TJ. Murder or mercy? Hurricane Katrina and the need for disaster training. N Engl J Med 2006;355(20):2067-9. 
109. Barry M, Hughes JM. Talking dirty —the politics of clean water and sanitation. N Engl J Med 2008;359(8):784-7.

110. Bonnett CJ, Peery BN, Cantrill SV, et al. Surge capacity: a proposed conceptual framework. Am J Emerg Med 2007;25(3):297-306.

111. Devereaux A, Christian MD, Dichter JR, et al. Summary of suggestions from the Task Force for Mass Critical Care summit, January 26-27, 2007. Chest 2008; 133(5 Suppl):1S-7S.

112. Sternberg E, Lee GC, Huard D. Counting crises: US hospital evacuations, 1971-1999. Prehospital Disaster Med 2004;19(2):150-7.

113. Shatz DV, Wolcott K, Fairburn JB. Response to hurricane disasters. Surg Clin North Am 2006;86(3):545-55.

114. Blackwell T, Bosse M. Use of an innovative design mobile hospital in the medical response to Hurricane Katrina. Ann Emerg Med 2007;49(5):580-8.

115. Boyajian-O'Neill LA, Gronewold LM, Glaros AG, et al. Physician licensure during disasters: a National Survey of State Medical Boards. JAMA 2008;299(2):169-71.

116. Nates JL. Combined external and internal hospital disaster: impact and response in a Houston trauma center intensive care unit. Crit Care Med 2004; 32(3):686-90.

117. Schultz $\mathrm{CH}$, Koenig $\mathrm{KL}$, Lewis RJ. Implications of hospital evacuation after the Northridge, California, earthquake. N Engl J Med 2003;348(14):1349-55.

118. Schultz $\mathrm{CH}$, Koenig KL, Auf der Heide $\mathrm{E}$, et al. Benchmarking for hospital evacuation: a critical data collection tool. Prehospital Disaster Med 2005;20(5): 331-42.

119. Hawryluck L, Lapinsky SE, Stewart TE. Clinical review: SARS—lessons in disaster management. Crit Care 2005;9(4):384-9.

120. Mattox KL. Hurricanes Katrina and Rita: role of individuals and collaborative networks in mobilizing/coordinating societal and professional resources for major disasters. Crit Care 2006;10(1):205.

121. Greenough PG, Lappi MD, Hsu EB, et al. Burden of disease and health status among Hurricane Katrina-displaced persons in shelters: a population-based cluster sample. Ann Emerg Med 2008;51(4):426-32.

122. Vest JR, Valadez AM. Health conditions and risk factors of sheltered persons displaced by Hurricane Katrina. Prehospital Disaster Med 2006;21(2 Suppl 2): 55-8.

123. Howe E, Victor D, Price EG. Chief complaints, diagnoses, and medications prescribed seven weeks post-Katrina in New Orleans. Prehospital Disaster Med 2008;23(1):41-7.

124. Arnold JL. Disaster myths and Hurricane Katrina 2005: Can public officials and the media learn to provide responsible crisis communication during disasters? Prehospital Disaster Med 2006;21(1):1-3.

125. Burkle FM Jr, Noji EK. Health and politics in the 2003 war with Iraq: lessons learned. Lancet 2004;364(9442):1371-5.

126. Department of Defense. U.S. casualty status 2008. Available at: http://www. defenselink.mil/news/casualty.pdf. Accessed Sep 6, 2008.

127. Grathwohl KW, Venticinque SG. Organizational characteristics of the austere intensive care unit: the evolution of military trauma and critical care medicine; applications for civilian medical care systems. Crit Care Med 2008;36 (Suppl 7):S275-83.

128. Venticinque SG, Grathwohl KW. Critical care in the austere environment: providing exceptional care in unusual places. Crit Care Med 2008;36(Suppl 7): S284-92. 
129. Johannigman JA. Maintaining the continuum of en route care. Crit Care Med 2008;36(Suppl 7):S377-82.

130. Gawande A. Casualties of war-military care for the wounded from Iraq and Afghanistan. N Engl J Med 2004;351(24):2471-5.

131. Roudebush JG. Today's commitment: Transforming military medicine. Air Force Defense Strategy and Transformation Seminar Series. Washington, DC; November 15, 2006.

132. Beninati W, Meyer MT, Carter TE. The critical care air transport program. Crit Care Med 2008;36(7 Suppl):S370-6.

133. Rice DH, Kotti G, Beninati W. Clinical review: critical care transport and austere critical care. Crit Care 2008;12(2):207.

134. Fang R, Pruitt VM, Dorlac GR, et al. Critical care at Landstuhl Regional Medical Center. Crit Care Med 2008;36(Suppl 7):S383-7.

135. Colombo CJ, Mount CA, Popa CA. Critical care medicine at Walter Reed Army Medical Center in support of the global war on terrorism. Crit Care Med 2008; 36(Suppl 7):S388-94.

136. Kashani KB, Farmer JC. The support of severe respiratory failure beyond the hospital and during transportation. Curr Opin Crit Care 2006;12(1):43-9. 